\title{
Integration of SHRP2 Solutions into Civil Engineering Curricula at Rowan, Temple, Villanova, and West Virginia Universities
}

Dr. Yusuf A Mehta, Rowan University

Dr. Mehta is a Professor at the Department of Civil and Environmental Engineering at Rowan University. Dr. Mehta has extensive experience in teaching pavement materials and pavement systems. Dr. Mehta has published several technical and educational papers in leading professional organizations.

\section{Dr. Ayman Ali, Rowan University}

Dr. Parth Bhavsar, Rowan University

Parth Bhavsar, is an assistant professor in the Department of Civil and Environmental Engineering at Rowan University. His research interests include Intelligent Transportation System (ITS), Connected, Autonomous, and connected-automated Vehicle Technologies, Transportation Data Analytics, and Alternative Fuel Vehicles. Dr. Bhavsar has published in peer reviewed journals such as the Transportation Research Part C: Emerging Technology, Transportation Research Part D: Transport and the Environment and Transportation Research Record Journal of the Transportation Research Board. Dr. Bhavsar was previously a postdoctoral fellow in a connected vehicle research program in the Glenn Department of Civil Engineering at Clemson University, where he worked on several connected vehicle technology research projects. Dr. Bhavsar received his Ph.D. degree in 2013 and his M.S. degree in 2006 from Clemson University. His Ph.D. dissertation focused on development of an evaluation framework for connected vehicle technology supported alternative fuel vehicles. Dr. Bhavsar also has three years of experience in the private sector in developing transportation engineering and planning solutions, specifically traffic micro-simulation projects.

\section{Dr. Seri Park, Villanova University}

Seri Park, PhD, PTP, is an Assistant Professor in the Civil and Environmental Engineering Department at Villanova University. She is serving as a member of the Undergraduate Curriculum Committee for the CEE Department. She is also the faculty advisor of the Institute of Transportation Engineers (ITE) Student Chapter at Villanova and member of Villanova's Transportation Subcommittee under President's Environmental Sustainability Committee. In addition to those duties at Villanova University, she is also Panel Member of various research projects sponsored by The National Academies and University Representative of Transportation research Board. Her teaching and research area include various aspects of transportation engineering, traffic safety, and sustainable infrastructure.

\section{Dr. Kakan C Dey, West Virginia University}




\section{Integration of SHRP2 Solutions into Civil Engineering Curricula at Rowan, Temple, Villanova, and West Virginia Universities}

\section{Introduction}

The Strategic Highway Research Program 2 (SHRP2) provides funding to research efforts intended to address state and local transportation issues. The outcomes of these research studies are industry-ready products which not only solve local transportation challenges but also can be utilized for nation-wide adoption. These products were developed in partnership with state agencies (as a lead), consultants, and experts from academia. While these products are developed to improve national, state and local transportation system, the primary issue in implementing these products is training existing and future civil engineers. To address this problem, the SHRP2 education connection program was developed that facilitates integration of these products in existing civil engineering curriculum. The SHRP 2 Education Connection program serves as an excellent pedagogical tool to each civil engineering student by providing knowledge of SHRP2 products and their impacts on community before they start their careers as transportation engineer. In the first round of SHRP2 Education Connection, faculty members from Rowan University had successfully integrated (SHRP2) solutions and products in the CEE curriculum (i.e., in fall 2015 and spring 2016 semesters).

Mehta et al [1] reported that the vertical integration of SHRP2 products from freshman year to doctoral level resulted, not only in an increased understanding of the role of each SHRP2 product in solving transportation challenges, but also increased students' awareness of how these products are improving lives. The incorporation of these modules within the CEE curricula are in line with the CEE Department's mission to prepare the next generation of civil engineering professionals. The goal of this paper is to present the effectiveness of the proposed SHRP2 product integration approach at three universities (specifically second iteration at Rowan University and first iteration at West Virginia and Villanova University) and the impacts of such approach on students' learning and interests in transportation related topics.

\section{Outcomes SHRP2 Education Connection Phase I at Rowan University}

During the first round of SHRP2 Education Connection, lectures were recorded and are available online at http://www.rowan.edu/creates/research/projects/videos.html. Access to these videos is open to everyone who chooses to adopt the SHRP2 modules in their classroom. The research team has delivered the module in Civil Engineering materials course at Rowan University in a flipped classroom format as a test case and to evaluate its long-term feasibility. The students were provided links to the videos through the university Blackboard system. An assessment was conducted in the form of a multiple choice quiz and an evaluation survey was provided immediately after the students watched the video. The students were asked to complete a multiplechoice quiz immediately after seeing the video to assess their understanding of the SHRP2. The students were given bonus points for attempting these modules. All students of that class viewed the video even though it was a bonus.

The research team has made a significant effort to incorporate SHRP2 products as an inherent part of the CEE courses. To build upon previous success and strengthen the vertical integration method, the research team (1) Continued existing practice by teaching relevant SHRP2 products immediately after the relevant theoretical content; (2) Expanded offering of flipped classroom 
model to the other five courses; and (3) Evaluated the feasibility of transferring the vertical integration method by (a) collaborating with other institutions and (b) Integrating selected modules in the National Summer Transportation Institute (NSTI) program (Figure 1).

\section{Continue Existing Practice}

- Utilize recorded modules for flipped classroom

- Evaluate students' understanding

\section{Strengthen Vertical Integration}

- Integrate flipped classroom model to new courses

- Evaluate feasibility of flipped classroom model

- Evaluate students' understanding

\section{Evaluate Transferability}

- Collaborate with other institutions

- Integrate SHRP2 products in National Summer Transportation Institute (NSTI) Program modules

- Post-implementation Webinar on 'Lessons Learned'

Figure 1 Vertical Integration of Modules

\section{Brief Description of Vertical Integration Approach}

Rowan University's team identified seven courses at undergraduate and graduate level to incorporate SHRP2 products. Figure 2 shows the list of courses identified at each level for vertical integration of SHRP2 products. As shown in the figure, the SHRP2 products were introduced and integrated from freshman level to doctoral level in core courses of civil engineering curriculum. Furthermore, Rowan University identified two graduate courses, which are not core courses, for selected SHRP2 products. While the central flow chart in Figure 2 presents a vertical integration model adopted by Rowan University, the side arrows presents method of integration, which were (1) flipped classroom model and/or (2) group projects based on SHRP2 products. 


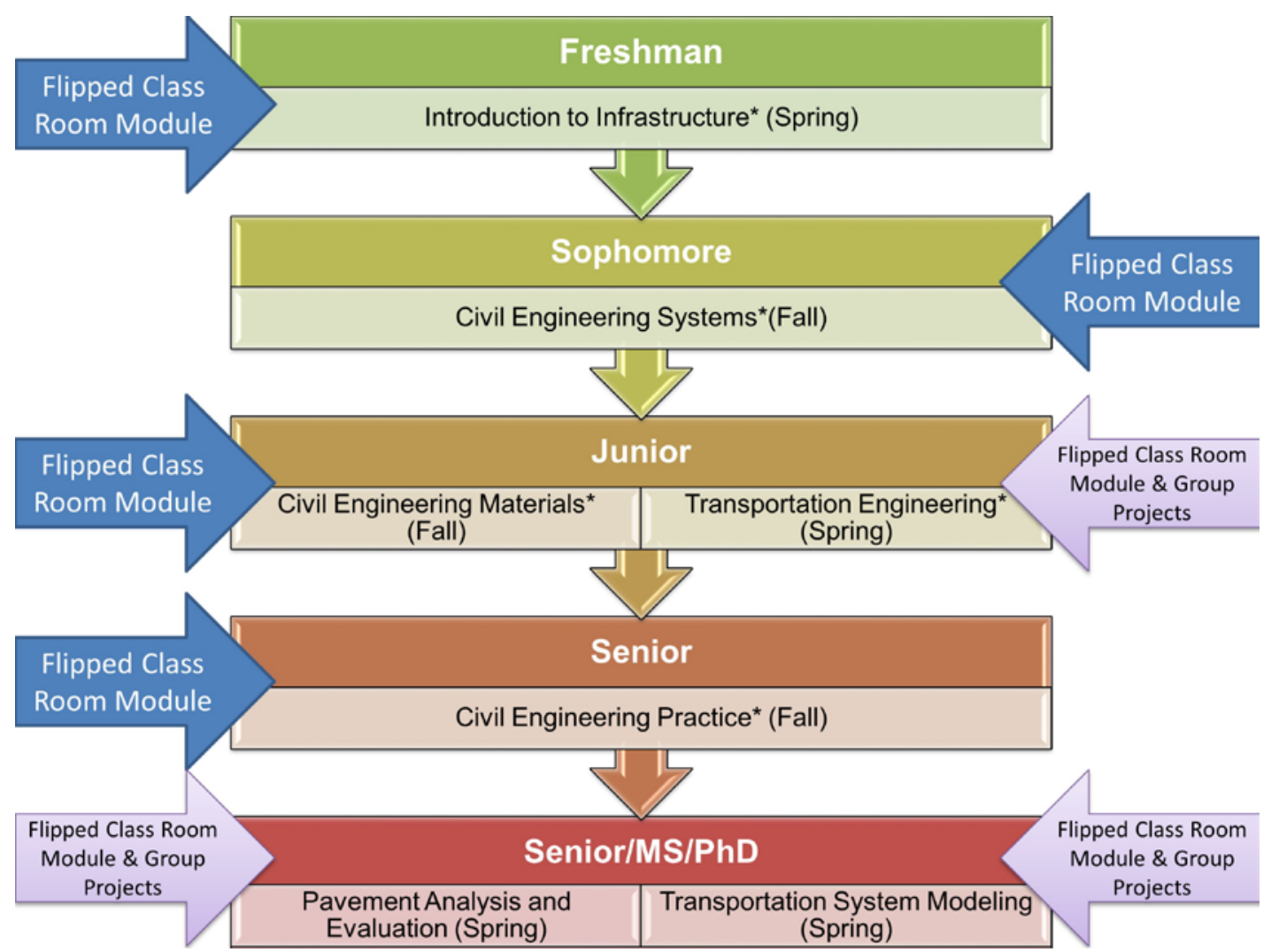

Figure 2 Proposed integration approach

\section{Introduction of SHRP2 to High school students (9-12) at National Summer Transportation Institute (NSTI) hosted at Rowan University}

In addition to vertical integration of existing CEE curricula, Rowan University team utilized the NSTI platform to educate high school students (Grades 9 through 12) about SHRP2 products. The research team developed and taught a class module that introduced the SHRP2 program and products and a sensitivity analysis module focusing on SHRP2 reliability products. The research team conducted pre and post assessment of learning outcomes of these modules as per the protocols established for NSTI.

\section{SHRP2 Products' Vertical Integration at Other Universities}

The faculty at Rowan University developed a collaboration plan to evaluate the transferability of the vertical integration model. The purpose of the collaboration effort was to evaluate the feasibility of implementing vertical integration method developed by Rowan University in other institutions. The research team also identified faculty members from Temple, Villanova, and West Virginia universities for the pilot study. The diversity of the student body and the student class size (30 versus 80 ) varies between the four institutions (private versus public). Evaluating the efficacy of the SHRP2 module between these institutions will provide insight on how these modules will perform across a broad spectrum of institutions in the US.

The three faculty members who were willing to participate included: Dr. Seri Park from Villanova University (VU), Dr. Ahmed Faheem from Temple University (TU) and Dr. Kakanchandra Dey from West Virginia University (WVU). These faculty members directly benefitted from the existing flipped classroom modules developed by Rowan's research team as 
well as the additional flipped classroom modules developed as part of SHRP2 Education Connection Phase II. Table 2 shows various courses taught by each faculty member in their respective institution. As presented in the table, Dr. Seri Park and Dr. Kakanchandra Dey instruct Transportation Engineering, while Dr. Ahmed Faheem instructs Materials and Pavement related courses.

Table 2. Integration of SHRP2 Products in Other Three Institutions

\begin{tabular}{|c|c|c|}
\hline CEE course & Level & Instructor(s) \\
\hline \multicolumn{3}{|l|}{ Temple University (TU) } \\
\hline Transportation Engineering Materials & Senior \Graduate & \multirow{3}{*}{ Ahmed Faheem } \\
\hline Structural Design of Pavements & SeniorlGraduate & \\
\hline Pavement Maintenance and Rehabilitation & Senior\Graduate & \\
\hline \multicolumn{3}{|l|}{ Villanova University (VU) } \\
\hline Introduction to Transportation Engineering & Sophomore & \multirow{3}{*}{ Seri Park } \\
\hline Engineering Economics & Junior & \\
\hline Transportation systems Design & Senior & \\
\hline \multicolumn{3}{|l|}{ West Virginia University (WVU) } \\
\hline Urban Transportation Planning & Senior\Graduate & \multirow{2}{*}{ Kakanchandra Dey } \\
\hline Traffic Engineering and Operations & Senior\Graduate & \\
\hline
\end{tabular}

\section{Evaluation of Vertical Integration Approach}

Four strategies were developed and executed to evaluate the effectiveness of the vertical SHRP2 product integration approach. These strategies include:

1) Administer a pre-survey of the class to assess the understanding of SHRP2 products (the details of the pre and post-survey are explained later in the paper)

2) Require the students to view the pre-recorded class modules and assess learning outcomes and students' understanding through a quiz related to the module. Each class of students will get one week to watch the relevant video module and attempt the quiz.

3) Dr. Mehta and Dr. Bhavsar, will then conduct a 20-30 minute discussion in the class of what the students learnt from the video module, answer the assessment questions, and address any follow-up questions. During this time, any additional information and updates, such as FHWA webinar, discussion of new products will be shared with the students.

4) Conduct a post-survey of the class to assess understanding of the SHRP2 products.

At Temple, Villanova and West Virginia universities, the participating faculty members explained to the students how the SHPR2 products will be presented in class. The faculty members in the different institutions conducted pre- and post-assessment of the SHRP2 module. In addition, they provided feedback to Rowan University about the following: a) What worked and what did not? and b) What changes, if any, should be made either at Rowan or their own institution to ensure seamless transferability to a larger number of institutions in the US.

The faculty members from Villanova and West Virginia University also collaborated for the spring 2017 semester to accelerate the integration process of SHRP2 product in their respective CEE curriculum. The faculty from Rowan University provided links to recorded video, and survey instruments to both faculty members. Additional guidance was provided via online conferencing venues as needed to all participating faculty members.

Pre- and Post-Implementation Surveys 
In addition to the ABET required course evaluation survey, Rowan University team have developed pre- and post-implementation surveys to quantify the impacts of SHRP2 products' integration into existing courses. As mentioned earlier, these surveys were administered as part of the integration of the existing modules in the flipped classroom. However, since the development of new class modules in the transportation classes is different for various courses, the proposed post-assessment may be different. Samples of the pre- and post-implementation surveys are shown in Table 3 and 4, respectively. The surveys were modified slightly from the version presented in Mehta et al [1]. The goal of the surveys was to gain a better understanding of how students are perceiving and utilizing SHRP2 products at various universities participating in this study.

Table 3: An Example of the Developed Pre-Teaching Survey.

Pre-Survey (Questions Pertaining to Course)

Question No. 1: Please specify how much you agree/disagree with the following statement: I have the necessary background from previous courses about Strategic Highway Research Program (SHRP2) products.

(1) Strongly Disagree

(2) Disagree

(3) Neutral

(4) Agree

(5) Strongly Agree

Question No. 2: Please specify how much you agree/disagree with the following statement: I have used SHRP2 products for my projects/assignments in my previous courses.

(1) Strongly Disagree

(2) Disagree

(3) Neutral

(4) Agree

(5) Strongly Agree

Question No. 3: Please specify how much you agree/disagree with the following statement: SHRP2 products are the highly innovative tools and processes resulting from SHRP2 (research programs funded by US Department of Transportation), and offers the opportunity to bring state-of-the-practice solutions into the classroom. Would you be interested in learning these products as a part of this course?

(1) Strongly Disagree

(2) Disagree

(3) Neutral

(4) Agree

(5) Strongly Agree

Question No. 4: Please select how likely are you to use SHRP2 products in your class project.

Based on your current knowledge of SHRP2 product, how likely will you be willing to use these products in your current and future course projects, assignments, and real-world projects?

(1) Extremely Unlikely

(2) Unlikely

(3) Maybe

(4) Likely

(5) Extremely Likely

Question No. 5: Please specify how much you agree/disagree with the following statement: 
Based on my current knowledge of SHRP2 products, I strongly believe that these products will improve my skills as a transportation engineer.

(1) Strongly Disagree

(2) Disagree

(3) Neutral

(4) Agree

(5) Strongly Agree

Table 4: An Example of the Developed Post-Teaching Survey.

Post-Survey (Questions Pertaining to Course)

\section{Introduction:}

The instructor presented SHRP2 products in the class which can be used for various transportation engineering and planning applications. Answer following questions based on the knowledge you gained regarding these SHRP2 tools.

Question No. 1: Please specify how much you agree/disagree with the following statement: I had the necessary background regarding SHRP2 products and research projects from previous course(s).

(1) Strongly Disagree

(2) Disagree

(3) Neutral

(4) Agree

(5) Strongly Disagree

Question No. 2: Please specify how much you agree/disagree with the following statement: I will use SHRP2 products in my future class(es) assignments and real-world projects.

(1) Strongly Disagree

(2) Disagree

(3) Neutral

(4) Agree

(5) Strongly Agree

Question No. 3: I have used (OR I am planning to use) SHRP2 product(s) in my class assignment and/or project(s).

(1) Yes (if yes, go to question 4)

(2) No

Question No. 4: Please enter name/title of the SHRP2 product(s) that you have used.

(1) Enter Text

Question No. 5: The above SHRP2 product(s) have increased quality of my class assignments/projects.

(1) Strongly Disagree

(2) Disagree

(3) Neutral

(4) Agree

(5) Strongly Agree

Question No. 6: The above SHRP2 product(s) have increased my productivity.

(1) Strongly Disagree

(2) Disagree 


\begin{tabular}{l} 
(3) Neutral \\
(4) Agree \\
(5) Strongly Agree \\
\hline Questions No. 7: Provide at least two examples on how the SHRP2 products cover in the \\
course will impact Transportation Engineering
\end{tabular}

(1) Enter Text

Questions No. 8: Based on the understanding of the SHRP2 products, what are the other products/tools that you would like to see in SHRP2 modules?

\section{Results}

(1) Enter Text

This section presents and discusses results obtained in Fall 2017 after conducting the pre- and postteaching surveys. The classes had engineering students from various levels (i.e., sophomore through senior/grad levels). Figures 3 and 4 shows the results of the pre-survey, and Figures 5 and 6 shows the results of post-survey.

Figure 3 presents the percentage breakdown of responses obtained for Pre-Teaching Survey. As can be seen from this figure, the majority of surveyed undergraduate and graduate students had no prior knowledge (i.e., either answered strongly disagree, disagree, or neutral) of SHRP2 program or its products. Figure 3 also presents that some of junior, senior and graduate students at Rowan University had prior knowledge of SHRP2 products, an expected result as this is the second iteration of vertical integration process at Rowan University. The results from Villanova (VU) and West Virginia Universities (WVU) indicate that majority of the students did not have initial knowledge. This result is expected as this was the first iteration of SHRP2 product integration at Villanova and West Virginia Universities.

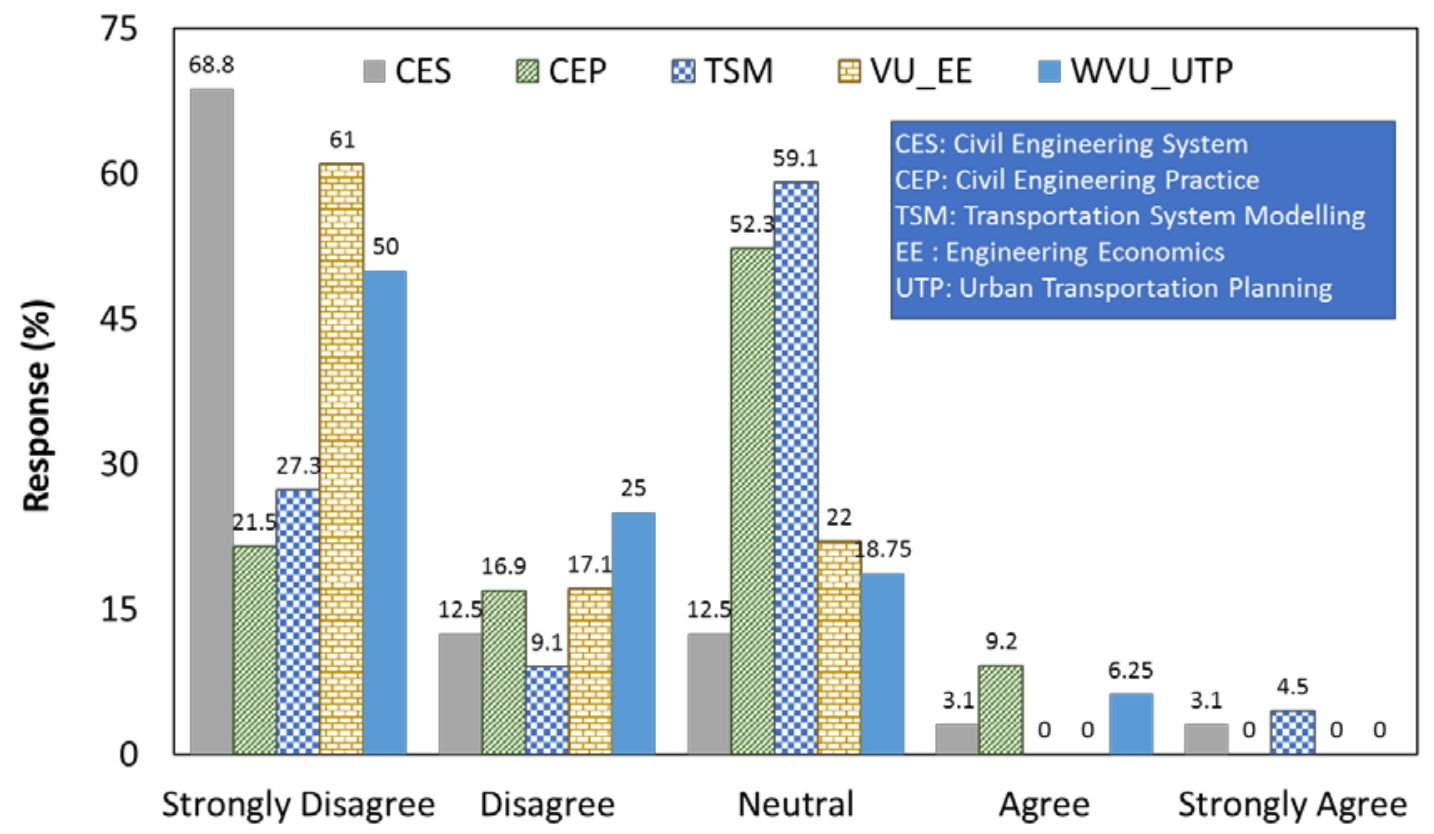

Figure 3. Knowledge of SHRP2 Products (Pre-Survey Results in percentage)

Figures 4 and 5 present responses for pre-teaching and post-teaching survey questions related to students' interest in learning about SHRP2 products. As shown in Figures 4 and 5, the majority of the surveyed students, regardless of their academic level, generally expressed their 
interest in learning about SHRP2 products (i.e., answered with agree or strongly agree). Figure 4 presents pre-survey results for which the instructors did not provide any brief introduction other than the description provided in question 3 of pre-survey. Figure 5 presents post-teaching survey results. For the CE practice class, while majority of students were interested in SHRP2 products, 21.1 percent disagreed after the introduction. This was a second iteration of SHRP2 integration at Rowan University. However, the first iteration did not include all required courses of CEE curriculum. This suggests that several students in CE Practice class learned about SHRP2 products for the first time. Furthermore, the one teaching module of introduction of SHRP2 products in the CE Practice class included introduction of the SHRP2 and SHRP2 Education Connection program and brief introduction of selected SHRP2 products. Thus, limited integration of SHRP2 products at the senior course level was not able to improve number of students interested in SHRP2 products. This disinterest of senior students from CE Practice class at Rowan University, clearly indicates the need of extensive integration at every level. The extensive integration (such as using SHRP2 products for group-projects after detailed instructions in class) may encourage the senior students to utilize them in class project as well as real world projects.

At Villanova University, 27.8 percent of the students were disinterested after the introduction of SHRP2 products. It is important to note that students at Villanova and West Virginia University were introduced SHRP2 products for the first time. The instructors utilized video and presentation provided by Rowan University to introduce SHRP2 products. The results in Figure 5 indicates the need for increased collaboration between Rowan and Villanova and West Virginia Universities. The detailed dialog between instructors of all participating universities is planned in Spring 2018. This process is expected to improve future results.

Figures 4 \& 5 comparison also indicates that a senior level course at Rowan University and a junior level course at Villanova University presented post-survey results with certain students not interested in SHRP2 products. However, the senior/graduate level course at Rowan University and West Virginia University presented significantly positive trend showing majority of students interested in SHRP2 products. In both seniorlgraduate level courses, students were required to do certain exercise using selected SHRP2 products. This suggest that the student responses were positive when instructors integrated SHRP2 products in group assignment. Figures 6 and 7 present similar trend for Rowan, Villanova and West Virginia University as shown in Figures 4 and 5. 


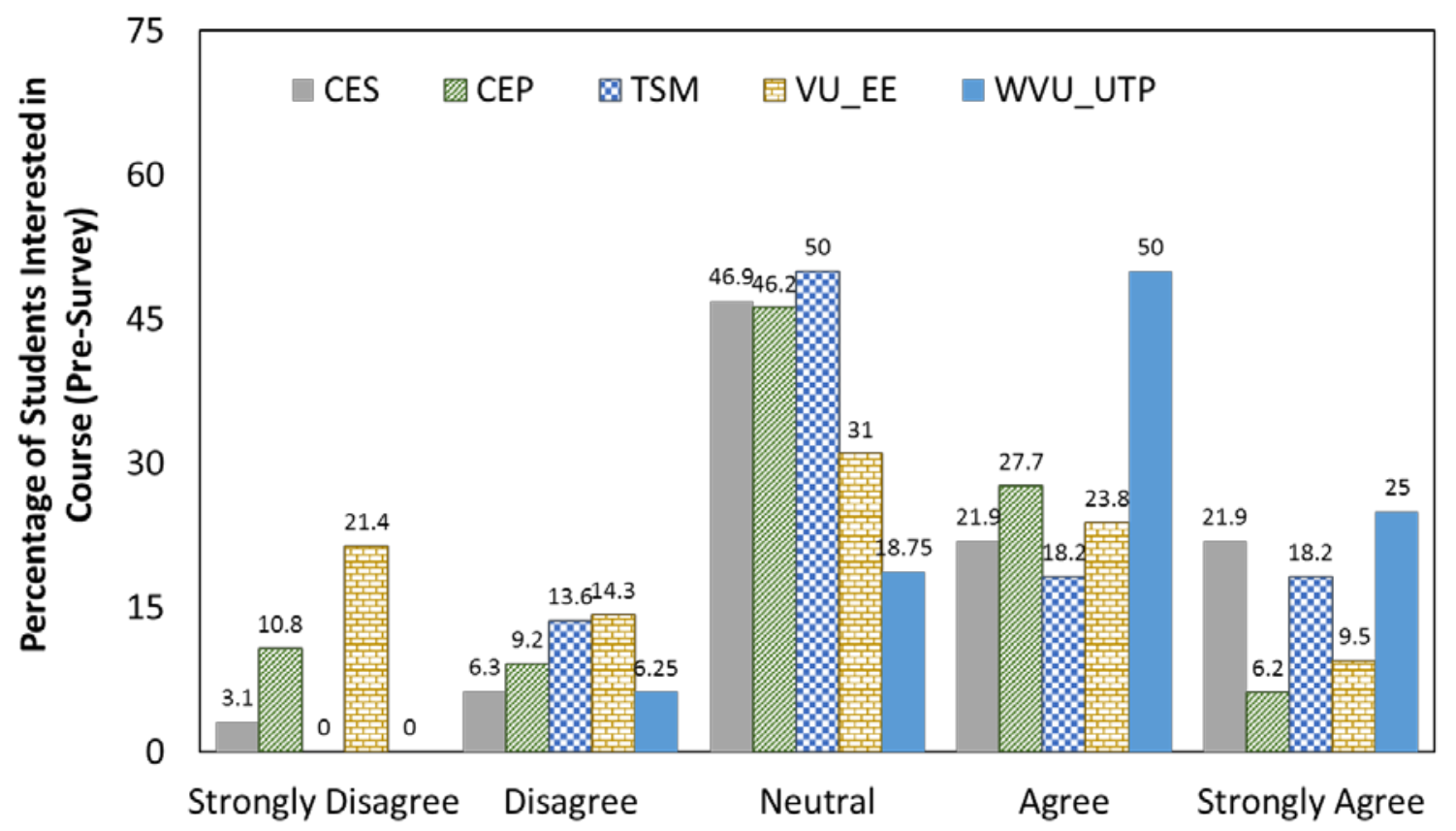

Figure 4. Percentage of Students in Interested in SHRP2 Products (Pre-Survey Results)

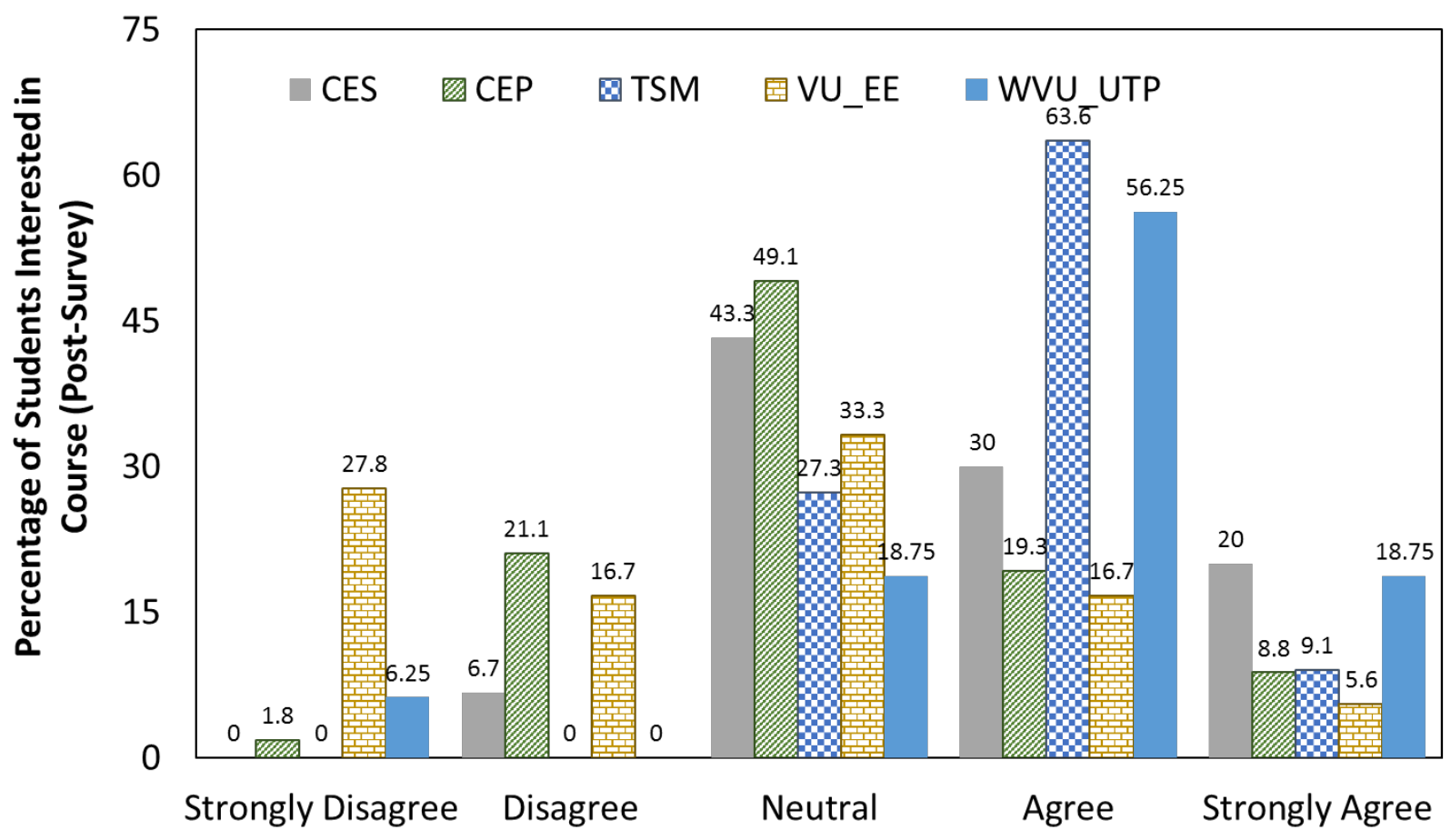

Figure 5. Percentage of Students in Interested in SHRP2 Products (Post-Survey Results) 


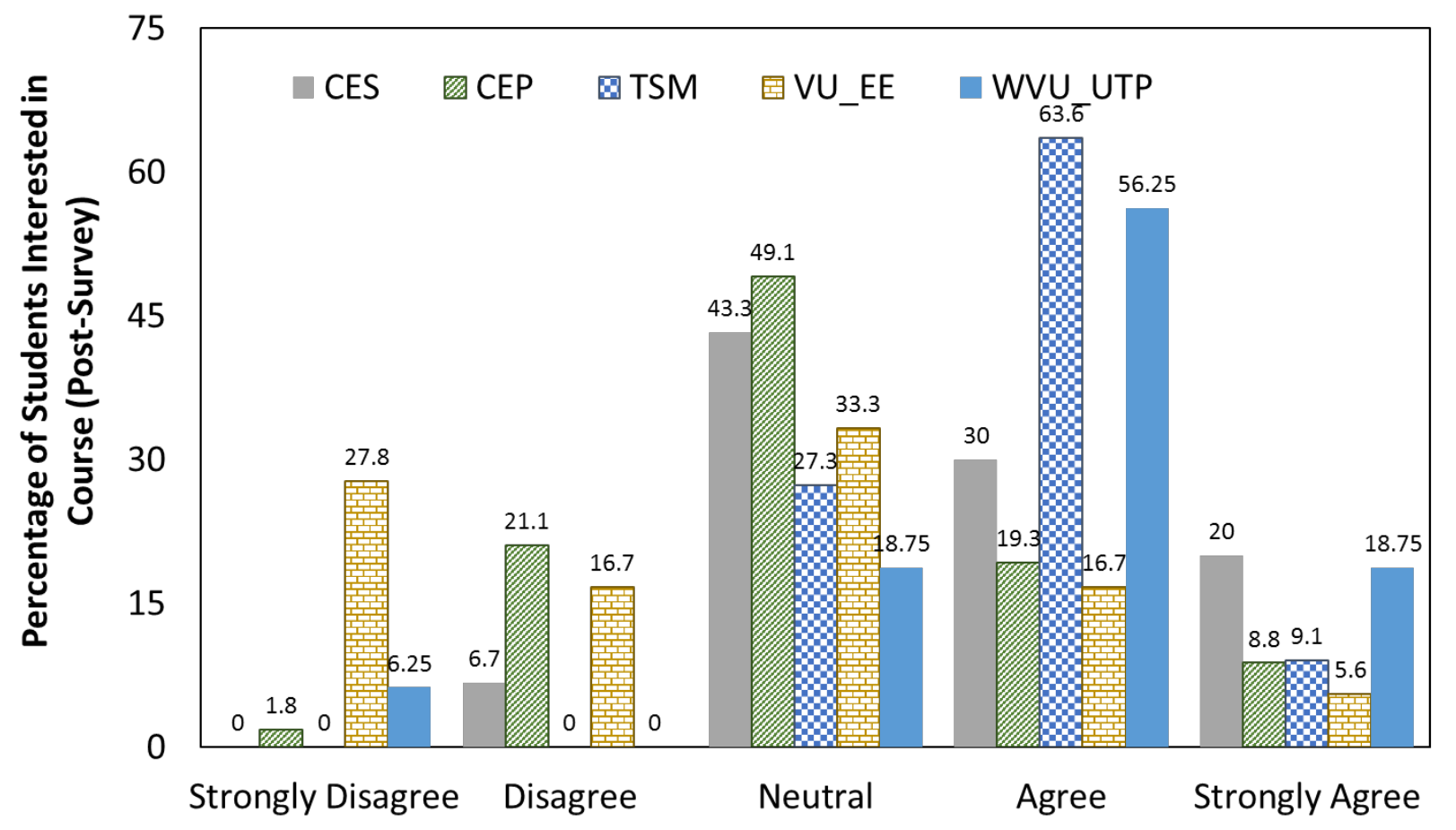

Figure 6. Percentage of Students Deeming SHRP2 Products Important (Pre-Survey Results)

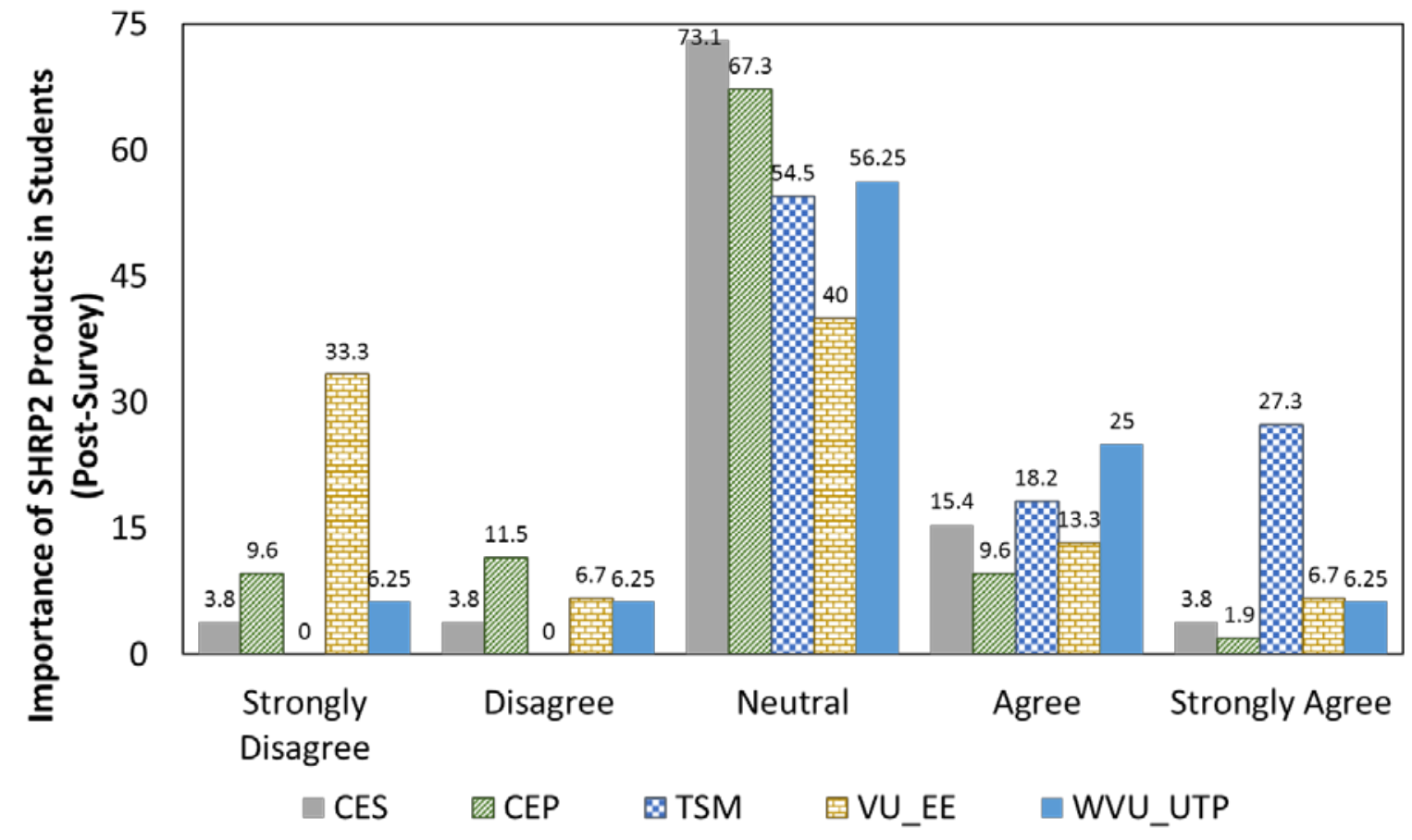

Figure 7. Percentage of Students Deeming SHRP2 Products Important (Post-Survey Results)

To summarize, the implemented approach was a success because students' interest in learning about SHRP2 products increased after implementing the proposed SHRP2 vertical integration approach. 


\section{Lessons Learned}

The approach was successful in achieving the objectives of the study after second iteration at Rowan University, however, further course-specific investigation and customization is required to improve the efficacy of the vertical integration approach. The detailed future recommendations are provided in the conclusions and recommendations section. Following list summarizes key points from the study.

$\square$ Students preferred the ease of use provided by the Econworks website (www.econworks.org). Graduate and senior students utilized economic analysis tools for their class projects.

$\square$ Integration of SHRP2 products in projects/assignments has more impact compared to presenting SHRP2 products.

$\square$ Comments from Villanova University instructor after the pre and post survey: Students were overall surprised to learn that there are various modules that could be readily used according to their own discipline.

$\square$ Comments from West Virginia University instructor after the pre and post survey: Students realized the importance of SHRP2 products, specifically when they are starting their career and working on real-world projects.

$\square$ Comments from Temple University instructor after introducing SHRP2 products to senior students: The availability of various SHRP2 products provides a support system for pavement engineers to amend experience with technical know-how, and provides future pavement engineers with the foundation to start working on solid ground of technical knowledge.

\section{Conclusions}

This paper presented an approach to vertically integrate SHRP2 products into Civil Engineering curricula. In this approach, several SHRP2 products were incorporated into class modules and presented to students from all four academic levels (i.e., freshman, sophomore, junior, and senior/grad levels). While Rowan University pioneered the vertical integration approach and currently implementing it for the second time, instructors from Rowan University also collaborated with faculty members from the participating universities to apply the SHPR2 integration approach at their respective CEE departments. The effectiveness of the proposed integration approach was evaluated by preparing pre- and post-teaching surveys that were administered before and after teaching SHRP2 modules. The prepared surveys focused on evaluating students' prior knowledge of SHRP2 products, their interest in learning SHRP2 products, and their opinion on the importance of SHRP products. Based on the results presented and the analysis conducted as a part of this study, the following conclusions were drawn:

- The proposed vertical integration approach was successful at integrating SHRP2 products in to CEE curricula. However, continuous implementation of the vertical integration in all CEE courses and refining the approach after every iteration will significantly change how SHRP2 products will be viewed and utilized by the next generation of transportation engineers.

- For Villanova and West Virginia Universities, students did not have any prior knowledge of the SHRP2 program or research products, the proposed approach involved briefly introducing SHRP2 introductory materials followed by the details of selected SHRP2 products. Considering that this was the first iteration at both universities, overall results are in favor of continuing the process of vertical integration. 
- The second iteration at Rowan University also presented opportunities for further investigating and refining the vertical integration approach within the selected CEE courses. In the next iteration at Rowan University, the instructors will (1) modify post-survey questions to gauge students' interest in transportation engineering; and (2) include detailed instructions for selected SHRP2 product in one of the class module.

- The strategy of using group and/or individual class project that includes use of SHRP2 products was significantly successful in senior/graduate level courses. It is important to note that the instructors provided basic background about the products and students learned selected product (economic analysis products) from the website, video and other resources provided by either SHRP2 education connection program or instructors.

\section{Future Recommendations}

The following list provides recommendations for successful future implementation of the proposed SHRP2 vertical integration approach. These recommendations are based on feedback from the SHRP2 module instructors.

- Incorporate more SHRP2 hands-on or field components.

- Develop more group and individual class projects that focus on utilizing SHRP2 products.

- Develop instructions to explain selected SHRP2 products in detail in class or laboratory settings.

- Modify existing survey questions for the next iteration to evaluate method of instructions and instructor.

- Develop an "instruction manual" to help instructors identify the most suitable approach for presenting SHRP2 products in class and laboratory settings. This manual can also serve as a basis for continuous integration of these products.

- Invite researchers and industry experts involved in developing SHRP2 products to serve as guest speakers.

\section{ACKNOWLEDGEMENT}

The authors would like to acknowledge the United States Department of Transportation and the Federal Highway Administration for funding this study through the SHRP2 Education Connection Program.

\section{REFERENCE}

1. Mehta, Y. A., \& Bhavsar, P., \& Ali, A. (2016, June), Integration of Strategic Highway Research Program 2 Products within the Entire Civil Engineering Curriculum Paper presented at 2016 ASEE Annual Conference \& Exposition, New Orleans, Louisiana. 10.18260/p.25432. 